\title{
A new species of Linan Hlaváč (Coleoptera, Staphylinidae, Pselaphinae) from Shenzhen, China
}

\author{
Qing-Hao Zhao', Wang Xu², Zi-Wei Yin' \\ I College of Life Sciences, Shanghai Normal University, Shanghai 200234, China 2 Shenzhen Environmental \\ Monitoring Center, Shenzhen 518049, Guangdong, China \\ Corresponding author: Zi-Wei Yin (pselaphinae@gmail.com)
}

Academic editor: Jan Klimaszewski | Received 15 April 2019 | Accepted 27 May 2019 | Published 2 July 2019

http://zoobank.org/555B0434-51EC-4788-8E45-383068COCAE8

Citation: Zhao Q-H, Xu W, Yin Z-W (2019) A new species of Linan Hlaváč (Coleoptera, Staphylinidae, Pselaphinae) from Shenzhen, China. ZooKeys 859: 63-68. https://doi.org/10.3897/zookeys.859.35465

\begin{abstract}
A new Chinese species of the genus Linan Hlaváč, 2003, L. qiniangmontis sp. nov., is described based on two male and three female specimens from sifted leaf litter samples at Qiniang Mountain, Shenzhen City, Guangdong. The species can be readily recognized and separated from all congeners based on the forms of the male antennae, the metaventral processes, and the aedeagus.
\end{abstract}

\section{Keywords}

Ant-loving beetles, southern China, taxonomy, Tyrini

\section{Introduction}

The Oriental genus Linan Hlaváč, 2003 belonging to the 'Pselaphodes complex' of genera (Hlaváć 2003; Yin et al. 2013a) is a small group containing 16 species distributed in China (16 spp.) and Thailand (1 sp.) (Hlaváč 2003; Yin et al. 2011, 2013b; Yin and Li 2012, 2013; Zhang et al. 2018). An identification key and distributional maps of the genus were recently provided by Zhang et al. (2018). A survey of the local coleopterous fauna in Shenzhen City has resulted in the discovery of the $17^{\text {th }}$ species of Linan, which is described here. 


\section{Materials and methods}

The material used in this paper is housed in the Insect Collection of Shanghai Normal University, Shanghai, China (SNUC). The text of the specimen labels is quoted verbatim, with original Chinese names listed in parentheses.

Dissected parts were preserved in Euparal on plastic slides that were placed on the same pins as the respective specimens. The habitus images were taken using a Canon 5D Mark III camera with a Canon MP-E 65mm f/2.8 1-5X Macro Lens, and a Canon MT-24EX Macro Twin Lite Flash used as the light source. Images of the morphological details were produced using a Canon G9 camera mounted to an Olympus CX31 microscope under transmitted light. Zerene Stacker (version 1.04) was used for image stacking. All images were modified and grouped into plates in Adobe Photoshop CS5 Extended.

The abdominal tergites and sternites are numbered following Chandler (2001) in Arabic (starting from the first visible segment) and Roman (reflecting true morphological position) numerals, e.g., tergite 1 (IV), or sternite 7 (IX).

\section{Taxonomy}

\section{Linan qiniangmontis sp. nov.}

http://zoobank.org/122313A9-AF98-429B-BBBE-D13402160D5C

Figs 1,2

Type material. Holotype: CHINA: ${ }^{\lambda}$ : 'China: Guangdong, Shenzhen City, Mt. Qiniang (七娘山), $23^{\circ} 32^{\prime} 28.73 " \mathrm{~N}, 114^{\circ} 35^{\prime} 8.46 " \mathrm{E}$, mixed leaf litter, sifted, $45 \mathrm{~m}$, 23.III.2019, Tang, Shuai, Zhao, Zhou \& Xia leg.' (SNUC). Paratypes: CHINA: 1 , 3 우, same label data as holotype (SNUC).

Diagnosis. Body length slightly less than $2.5 \mathrm{~mm}$. Male: antennal club almost simple, with antennomere IX slightly angulate at anteromesal corner; metaventral processes short and narrowing toward apex; protibiae with small denticle at apex; metacoxae with truncate, curved, ventral projection; aedeagus elongate, median lobe asymmetrically narrowed at apex. Female: identifiable only when in association with a male.

Description. Male (Fig. 1A). Body length (combined length of head, pronotum, elytra, and abdomen) $2.32-2.33 \mathrm{~mm}$. Head longer than wide, length from clypeal anterior margin to head base $0.52-0.54 \mathrm{~mm}$, width across eyes $0.48-0.49 \mathrm{~mm}$; eyes small, each composed of ca. 23 facets. Antennae elongate, $1.78-1.79 \mathrm{~mm}$ long, scape elongate, ca. 3.5 times as long as wide, antennomeres 2-8 each sub-moniliform, of similar width, antennal club (Fig. 2A) formed by antennomeres 9-11, antennomere 9 much longer than wide, broadening from base to apex, angulate at anteromesal corner (Fig. 2A, indicated by arrow), antennomere 10 slightly transverse, antennomere 11 truncate and broadest at base and narrowing apically, both antennomeres 10 and 11 simple. Pronotum (Fig. 2B) approximately as long as wide, with rounded lateral margins, length along midline $0.49-0.51 \mathrm{~mm}$, maximum width $0.49-0.52 \mathrm{~mm}$. Elytra 


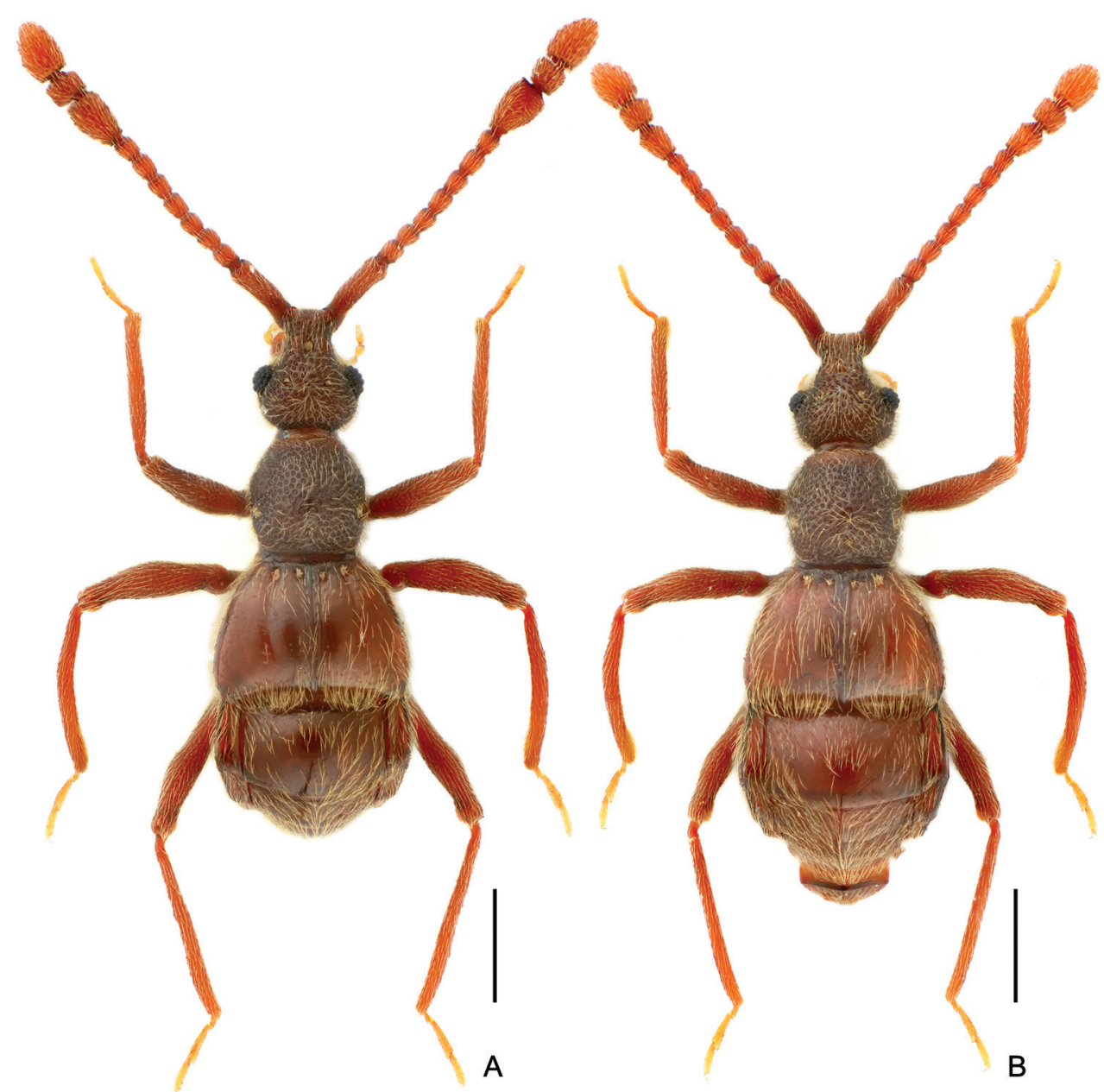

Figure I. Dorsal habitus of Linan qiniangmontis sp. nov. A male B female. Scale bars: $0.5 \mathrm{~mm}$.

strongly transverse, length along suture $0.56-0.57 \mathrm{~mm}$, maximum width $0.85-0.88$ $\mathrm{mm}$. Metaventral processes (Fig. 2C) short, narrowing apically. Protrochanters and profemora (Fig. 2D) simple, protibiae (Fig. 2E) with small but distinct denticle at apex; mesotrochanters, mesofemora, and mesotibiae (Fig. 2F) simple; metacoxae (Fig. $2 \mathrm{G}$ ) with truncate curved projection on ventral margin; metatrochanters, metafemora, and metatibiae simple. Abdomen approximately as wide as elytra, length of dorsally visible part along midline $0.74-0.77 \mathrm{~mm}$, maximum width $0.86-0.87 \mathrm{~mm}$; tergite 1 (IV) more than twice as long as tergite 2 (V); sternite 7 (IX) (Fig. 2H) semi-membranous, elongate. Length of aedeagus (Fig. 2I-K) $0.38-0.40 \mathrm{~mm}$; median lobe asymmetrical dorso-ventrally, narrowing apically with pointed apex; elongate parameres slightly exceeding apex of median lobe, with rounded apices; endophallus with one broad, rounded triangular sclerite, and one much shorter, elongate sclerite forked at apex. 


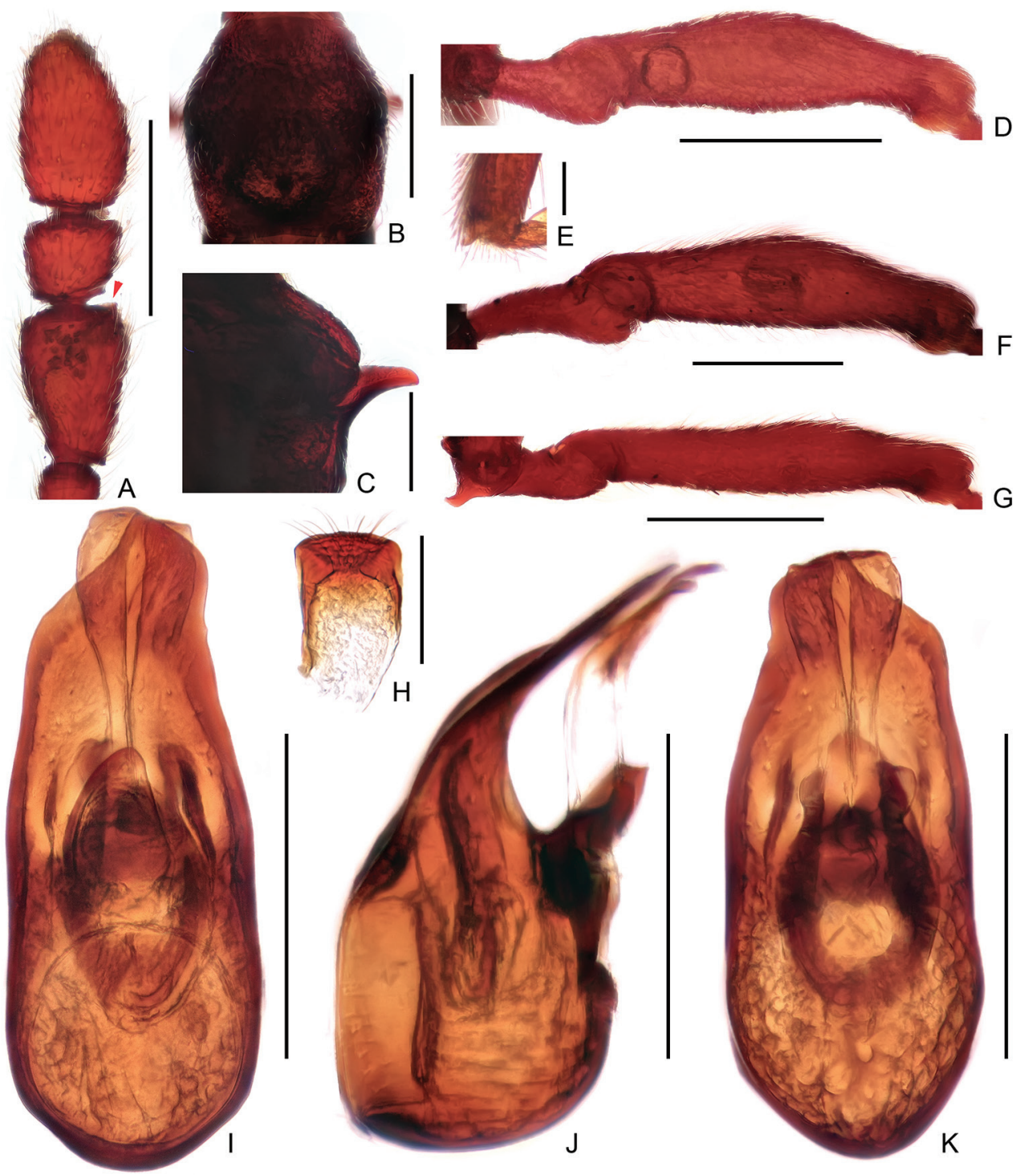

Figure 2. Male diagnostic features of Linan qiniangmontis sp. nov. A antennal club B pronotum $\mathbf{C}$ metaventral process, lateral $\mathbf{D}$ protrochanter and profemur $\mathbf{E}$ apex of protibia $\mathbf{F}$ mesotrochanter and mesofemur $\mathbf{G}$ metacoxa, metatrochanter, and metafemur $\mathbf{H}$ sternite IX I-K aedeagus, dorsal (I), lateral (J), and ventral (K). Scale bars: $0.3 \mathrm{~mm}(\mathbf{A}, \mathbf{B}, \mathbf{D}, \mathbf{F}, \mathbf{G}) ; 0.2 \mathrm{~mm}(\mathbf{C}, \mathbf{I}, \mathbf{J}, \mathbf{K}) ; 0.1 \mathrm{~mm}(\mathbf{H}) ; 0.05 \mathrm{~mm}(\mathbf{E})$.

Female. Similar to male in general morphology, with slightly shorter antennae and smaller eyes; antennae and legs simple; lacking metaventral processes. Eyes each composed of approximately 18 facets. Measurements (as of male): Body length 2.33-2.44 mm, length/width of head $0.53-0.55 / 0.49-0.51 \mathrm{~mm}$, length of antennae $1.63-1.70 \mathrm{~mm}$, length/width of pronotum $0.50-0.51 / 0.51 \mathrm{~mm}$, length/width of elytra $0.57 / 0.89-0.91 \mathrm{~mm}$, length/width of abdomen $0.72-0.81 / 0.92-0.93 \mathrm{~mm}$. 
Distribution. China: Guangdong.

Etymology. The new species epithet refers to the type locality of the new species, Qiniang Mountain.

Comparative notes. The new species is placed as a member of the L. chinensis group by the almost unmodified antennal clubs in the male. It is most similar to $L$. hujiayaoi Yin \& Li, 2013 and L. mulunensis Zhang, Li \& Yin, 2018 (both from Guangxi) in sharing modified male metacoxae. Linan qiniangmontis differs from both known species in the slightly angulate anteromesal corner of antennomere 9 (rounded in $L$. hujiayaoi and L. mulunensis), a different form of the metaventral processes (processes stouter in L. hujiayaoi and much more elongate in $L$. mulunensis), the lack of additional projections above the metacoxae (present in L. hujiayaoi and L. mulunensis), and a more elongate aedeagus with a different configuration of the endophallus.

\section{Acknowledgments}

Peter Hlavác (Czech University of Life Sciences Prague, Praha, Czech Republic) and Giorgio Sabella (Geologiche ed Ambientali dell'Università, Catania, Italy) reviewed the draft manuscript and provided helpful comments. The present study was supported by the National Natural Science Foundation of China (No. 31872965), the Shanghai 'Phosphor' Science Foundation, China (19QA1406600), the Shanghai Engineering Research Center of Plant Germplasm Resources (No. 17DZ2252700), and Shenzhen Environmental Monitoring Center, Shenzhen, China.

\section{References}

Chandler DS (2001) Biology, morphology and systematics of the ant-like litter beetles of Australia (Coleoptera: Staphylinidae: Pselaphinae). Memoirs on Entomology, International $15,560 \mathrm{pp}$.

Hlaváč P (2003) A taxonomic revision of the Tyrini of the Oriental region. II. Systematic study on the genus Pselaphodes and its allied genera (Coleoptera: Staphylinidae: Pselaphinae). Annales de la Société Entomologique de France 38: 283-297.

Yin Z-W, Hlaváč P, Li-Zhen Li (2013a) Further studies on the Pselaphodes complex of genera from China (Coleoptera, Staphylinidae, Pselaphinae). ZooKeys 275: 23-65. https://doi. org/10.3897/zookeys.275.4571

Yin Z-W, Li L-Z (2012) Notes on Michael Schülke's pselaphine collections from China. Tyrini. I. genera Labomimus Sharp, Linan Hlaváć and Pselaphodes Westwood (Coleoptera, Staphylinidae, Pselaphinae). ZooKeys 251: 83-118. https://doi.org/10.3897/zookeys.251.4099

Yin Z-W, Li L-Z (2013) Five new species of the genera Labomimus and Linan from Guangxi, South China (Coleoptera: Staphylinidae: Pselaphinae). Acta Entomologica Musei Nationalis Pragae 53: 141-153. 
Yin Z-W, Li L-Z, Zhao M-J (2011) A review of the genus Linan (Coleoptera: Staphylinidae: Pselaphinae). Acta Entomologica Musei Nationalis Pragae 51: 123-135.

Yin Z-W, Nomura S, Li L-Z (2013b) New species and new records of the Pselaphodes complex of genera (Staphylinidae: Pselaphinae: Tyrini) from China. Annales Zoologici 63: 343356. https://doi.org/10.3161/000345413X669595

Zhang Y-Q, Li L-Z, Yin Z-W (2018) Six new species and a new record of Linan Hlavác in China, with a key to species (Coleoptera, Staphylinidae, Pselaphinae). ZooKeys 793: 115-133. https://doi.org/10.3897/zookeys.793.27661 